\title{
Pathogenesis of ovine lentiviral encephalitis: derivation of a neurovirulent strain by in vivo passage
}

\author{
LE Craig ${ }^{1,2,3}$, D Sheffer ${ }^{4}$, AL Meyer ${ }^{1}$, D Hauer ${ }^{1}$, F Lechner $^{5}$, E Peterhans ${ }^{5}$, RJ Adams ${ }^{1}$, JE Clements ${ }^{1,6}$, \\ O Narayan ${ }^{4}$ and MC Zink Ni,2,3 $^{1,2}$ \\ ${ }^{1}$ Division of Comparative Medicine, ${ }^{2}$ Department of Pathology, ${ }^{6}$ Department Molecular Biology and Genetics, Johns \\ Hopkins University School of Medicine, ${ }^{3}$ Department Molecular Microbiology \& Immunology, Johns Hopkins School of \\ Public Health, Baltimore, Maryland, 21205, USA; ${ }^{4}$ Department Microbiology, Molecular Genetics $\&$ Immunology, \\ University of Kansas Medical Center, Kansas City, Kansas 66160, USA; ${ }^{5}$ Institute of Veterinary Virology, University of \\ Bern, Bern, Switzerland 3012
}

\begin{abstract}
The lentiviruses of sheep replicate almost exclusively in macrophages and cause chronic interstitial pneumonia, arthritis, and mastitis, but only rarely encephalitis. This study was undertaken to determine whether a nonneurovirulent field strain of ovine lentivirus isolated from joint fluid that replicated productively in lung and joint macrophages could be adapted to enter and replicate in the brain and cause encephalitis. The field isolate was passed seven times sequentially by intracerebral inoculation of sheep. The neuroadapted strain of virus caused severe encephalitis typical of visna in four of four sheep inoculated intracerebrally. The virus replicated to high titers in the brains of these animals and in cultured microglia. The inflammatory response in the brain was characterized by intense infiltrates of macrophages and $\mathrm{CD8}^{+}$and $\mathrm{CD4}^{+} \mathrm{T}$ cells. Many of the perivascular macrophages demonstrated TNF- $\alpha$ expression and there was upregulation of MHC Class II antigen expression on both inflammatory cells and endothelium. Inoculation of this neuroadapted virus into the bone marrow of three animals resulted in persistent infection and cell-associated viremia, but not encephalitis. Virus was not detected in brains from these animals, indicating that the virus was not neuroinvasive. These data suggest that neuroinvasiveness and neurovirulence are separate pathogenic determinants, both of which are required for the development of encephalitis during natural infection.
\end{abstract}

Keywords: animal; sheep; visna; retrovirus; brain

\section{Introduction}

The lentiviruses of sheep are the classical taxonomic prototypes of the family of slow retroviruses that includes the human immunodeficiency viruses. The ovine lentiviruses (OvLV) cause widespread infection in nature, disseminating mainly via colostrum, milk and respiratory exudates. The viruses persist for life in infected sheep and except for rare explosive outbreaks of disease in localized areas, the agents cause only sporadic clinical disease, mainly in adult animals after prolonged incubation periods (Narayan and Clements, 1989; Sigurdsson et al, 1957).

Correspondence: MC Zink DVM, PhD, Retrovirus Biology Laboratory, Traylor G-60, Division of Comparative Medicine Johns Hopkins University School of Medicine, 720 Rutland Ave, Baltimore, MD 21205 USA. Tel (410) 955-9770, Fax (410) 955-9823

Received 25 June 1997; revised 13 August 1997; accepted 12 September 1997
Chronic pneumonia is the main pathologic manifestation of ovine lentivirus infection in the United States (Oliver et al, 1981) hence the appellation, ovine progressive pneumonia virus (OPPV) (Cutlip et al, 1988; DeMartini et al, 1993). Animals with pneumonia usually become cachexic and frequently also have mastitis (Cutlip et al, 1985a; Kennedy-Stoskopf et al, 1985) and/or arthritis (Cutlip et al, 1985b). Rare infected animals also develop neurological disease characterized by wasting and progressive paralysis (Constable et al, 1996; Palsson, 1976; Schultheiss, 1985; Sheffield et al, 1980). Whether these various syndromes are caused by distinct virus strains or by a single multipotential virus is not known. Epidemiological studies of an outbreak of pneumonia (maedi) and encephalitis (visna) among Icelandic sheep following introduction of several rams from Europe in the 1950s suggested that the neurological and pneumo- 
nic disease syndromes may be caused by different strains of virus. Neurological disease (visna) was observed among sheep that were exposed to only two of the rams, suggesting that those two animals transmitted a unique strain of virus (Palsson, 1976).

Studies of primate lentiviruses also suggest that individual strains of virus are responsible for disease manifestations in specific tissues. In both the human (HIV) and simian (SIV) immunodeficiency viruses there is a correlation between the ability to replicate efficiently in macrophages and the ability to cause encephalopathy (Brinkmann et al, 1992; Cheng-Mayer et al, 1989; Desrosiers et al, 1991). Experimental data on SIV infection has shown that lymphocyte-tropic virus does not replicate productively in brain or cause neurological disease until the virus has undergone mutation and become macrophage-tropic (Desrosiers et al, 1991; Sharma et al, 1992). Further support for the existence of organ-specific viruses comes from observations that during infection in humans and macaques, viruses with different genetic and phenotypic markers were preferentially associated with specific tissues (Epstein et al, 1991; Koyanagi et al, 1987; Sharma et al, 1992).

Although Icelandic OvLV have been intracerebrally passaged to derive neurovirulent strains (Andrésson et al, 1994; Lutley et al, 1985), these viruses do not consistently cause disease in North American sheep (of British derivation). In this study, a North American field isolate was intracerebrally passaged in order to derive a neurovirulent virus to use in studies of the determinants of neurotropism (the ability to replicate in the brain), neurovirulence (the ability to cause disease in the brain), and neuroinvasiveness (the ability to invade the brain) in American sheep. A field virus isolated from synovial fluid replicated in joint, lung, and peripheral blood-derived macrophages, but was not detected in the brain. After multiple intracerebral passages of this virus in sheep, a neurovirulent strain of OvLV emerged that replicated in the brain and caused severe neurological lesions.

\section{Results}

In vivo virus passage

The scheme for sequential intracerebral passage of the virus is shown in Figure 1. The incidence and severity of encephalitis and pneumonia in each of these animals are shown in Figure 2. The brain and lung lesions were evaluated independently by two pathologists (MCZ, LEC). Pathological findings were most severe in periventricular white matter and included perivascular cuffs of lymphocytes and macrophages, diffuse parenchymal infiltration of lymphocytes and macrophages, and demyelination. Four areas of the brain were examined (basal ganglia, thalamus, midbrain, and medulla at the level of the obex) and each given a subjective rating for severity of 0 to $3 \quad(0=$ no lesions, $1=$ mild, $2=$ moderate, $3=$ severe). These ratings were combined to give the encephalitis score. The lung lesions were rated on a similar scale of 0 to 3 . The incidence and severity of encephalitis increased with passage of the virus whereas the incidence of pneumonia remained relatively constant.

Pathological changes in sheep infected with parent virus

Virus donor Fluid aspirated from the carpal joints of the donor animal (sheep 93) contained large numbers of macrophages from which ovine lentivirus (93 virus) was readily cultured. Postmortem examination of sheep 93 euthanized at 3 years of age revealed severe lymphocytic interstitial pneumonia (Figure 3), emaciation, and arthritis of the carpal joints with proliferative synovitis, lymphoplasmacytic inflammation, synovial mineralization and effusion into the carpal bursa. In situ hybridization
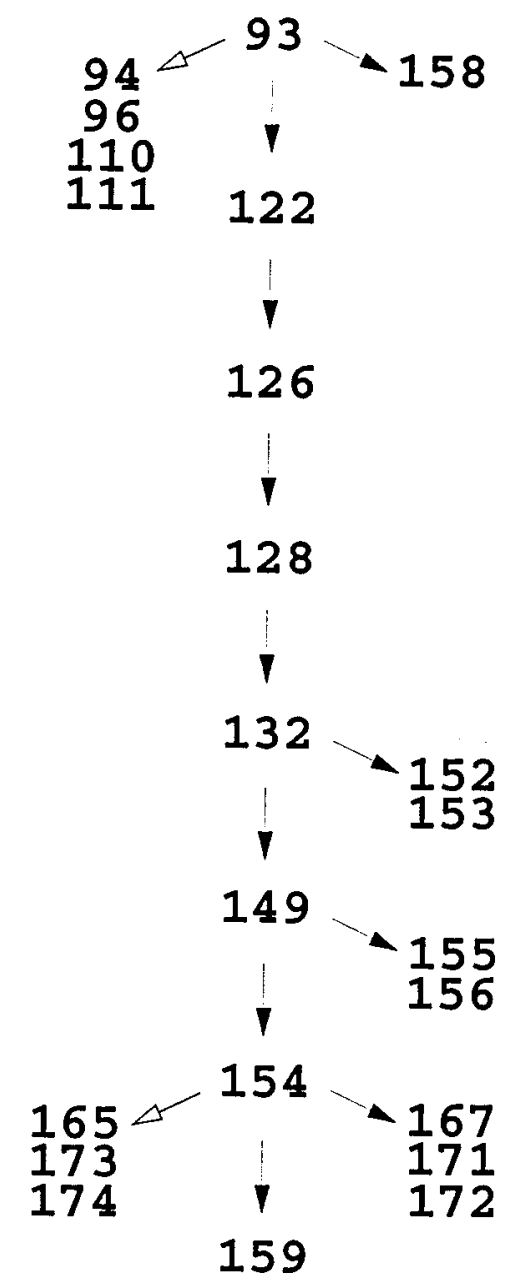

Figure 1 Intracerebral passage (solid arrows) and extra-cerebral inoculations (open arrows) of 23 sheep used in the derivation of a neurovirulent strain of OvLV. 
demonstrated macrophage-like cells containing viral RNA in the lung and carpal joints. There were no CNS lesions and virus was not detected by in situ hybridization or virus isolation in the brain or spinal cord.

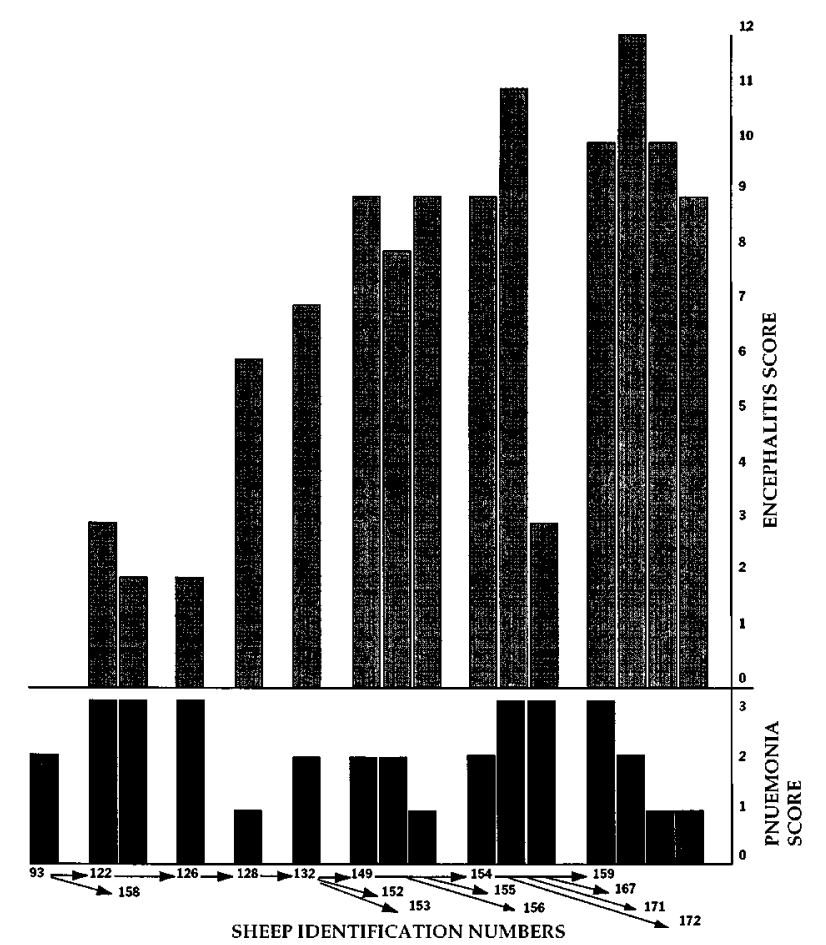

Figure 2 Summary of severity of brain and lung lesions in sheep used for intracerebral passage of virus. The encephalitis score was calculated by adding a score of 0 to 3 for the basal ganglia, thalamus, midbrain, and medulla. Pneumonia was also rated on a scale of 0 to 3 . The incidence and severity of encephalitis increased with passage of the virus whereas the incidence of pneumonia remained relatively constant.

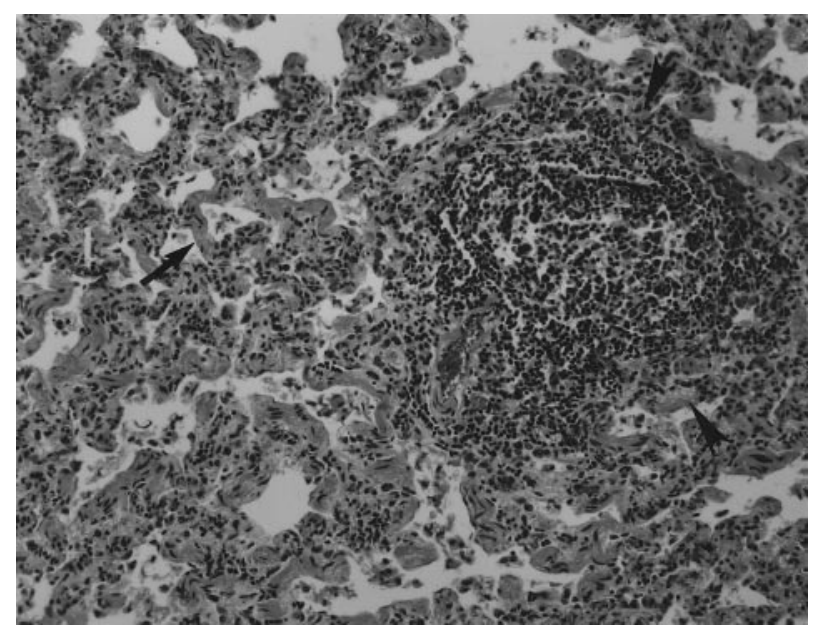

Figure 3 Lung from the donor sheep (sheep 93) demonstrating severe interstitial pneumonia with lymphoid infiltrates (arrowheads) and fibrosis of interalveolar septa (arrow). H\&E stain, magnification $\times 145$.
Intravenous $(I / V)$ inoculation with donor peripheral blood mononuclear cells (PBMC) Approximately $2 \times 10^{7} \mathrm{PBMC}$ from the donor sheep were inoculated $\mathrm{I} / \mathrm{V}$ and subcutaneously (S/Q) in equal amounts into four lambs (94, 96, 110, 111). Five additional inoculations of the same animals using PBMC from the donor sheep were performed 2-4 weeks apart and the animals were observed for up to 5 years. All animals became infected after the first inoculation as determined by recovery of virus from PBMC 2 weeks post-inoculation. Two sheep $(96,111)$ developed slowly progressive dyspnea and wasting and were euthanized 5 and 3 years post-inoculation, respectively. The virus burden in the blood of these two sheep was approximately one infected cell per $1 \times 10^{3}$ PBMC. The other two sheep $(94,110)$ remained healthy for 6 years and had less than one infectious cell per $1 \times 10^{6} \mathrm{PBMC}$. Thus, animals with clinical disease had a much higher virus burden than those with subclinical disease. Since none of the sheep in this group developed neutralizing antibodies to the input virus, the reduced viral load in the healthy animals could not be attributed to humoral control. Although all four of the sheep had some degree of interstitial pneumonia at necropsy, none had any lesions or detectable virus in the brain.

Intracerebral (I/C) inoculation with parent virus Two 6 month-old Border Leicester lambs $(122,158)$ were inoculated I/C with parent (93) virus. Both of these animals became infected but neither developed neutralizing antibodies to the virus. One (sheep 122) was euthanized at six weeks and its brain homogenate used for the passage experiment. It had only mild localized meningitis and rare perivascular cuffs in the area of inoculation. The other (sheep 158) was kept for long term observation (2 years). At necropsy it had moderate lymphocytic pneumonia and very mild lesions in the central nervous system (CNS) consisting of nonperiventricular perivascular cuffs. In neither of these animals was viral RNA detected in the brain by in situ hybridization. There were occasional cells containing viral RNA in the lungs, carpal synovium, lymph nodes and in the lamina propria of the small intestine. Results of immunohistochemical staining of brain tissue of sheep 158, euthanized at 2 years post-inoculation, are summarized in Table 1 . This animal had only scattered $\mathrm{T}$ cells in the brain parenchyma, with approximately equal numbers of $\mathrm{CD}^{+}$and $\mathrm{CD}^{+}$cells, and rare naive and $\gamma \delta \mathrm{T}$ cells. There was a moderate amount of MHC Class II expression in the brain. Lectin histochemistry demonstrated a moderate increase in the number of macrophages in areas of inflammation. Thus, intracerebral inoculation of the parental virus resulted in persistent systemic infection, minimal inflammation in lungs and synovium, and no evidence of infection in the brain. 
Pathological changes in sheep infected with neuroadapted virus

Intracerebral inoculation Four 6 month-old Border Leicester sheep $(159,167,171,172)$ were inoculated I/C with the neuroadapted virus and killed at 6 weeks to 1 year after inoculation. In all four sheep the lesions in the brain consisted of severe encephalitis with perivascular cuffing and intense macrophage- and lymphocyte-rich periventricular inflammation especially at the levels of the basal ganglia and thalamus. Luxol fast blue (LFB)/ periodic acid shift (PAS) staining showed demyelination in areas of intense periventricular inflammation (Figure 4) and perivascular macrophages containing numerous PAS-positive granules representing breakdown products of myelin. There were also foci of lymphocytic inflammation in cranial and cervical thoracic dorsal root ganglia.

All four sheep also had some degree of interstitial pneumonia typical of ovine progressive pneumonia characterized by peribronchial and perivascular lymphocytic infiltrates, thickened interalveolar septa, and occasional multinucleated cells. Bronchial and mediastinal lymph nodes had marked follicular and paracortical hyperplasia. Three sheep $(159,167,172)$ had moderate to marked lymphadenopathy of the submandibular, retropharyngeal, prescapular, mediastinal, and supramammary lymph nodes which was present throughout infection and was characterized by follicular hyperplasia and expansion of the paracortical zone.

One sheep (167) maintained for long-term evaluation became cachexic within the first year after inoculation. At necropsy, this animal had severe pneumonia typical of ovine lentivirus infection and such marked inflammation in the periventricular white matter that there was loss of virtually all of the neuropil in this region (Figure 5). Cells containing viral RNA were seen in the periventricular and perivascular areas of inflammation in the brain and

Table 1 Characterization of the inflammatory cells in the brains of sheep inoculated intracerebrally with parental and neuroadapted strains of OvLV

\begin{tabular}{lcc}
\hline & $\begin{array}{c}\text { Sheep } 158 \text { (innoculated } \\
\text { with }\end{array}$ parental virus) & $\begin{array}{c}\text { Sheep } \\
\text { with }\end{array}$ neuroadapted virus) \\
\hline CD2+cells & $+*$ & ++ \\
CD4+ Tcells & + & ++ \\
CD8+ Tcells & + & +++ \\
CD5+ cells & + & ++ \\
naive T cells & + & + \\
$\gamma \delta$ T cells & + & + \\
RCA+ cells & ++ & ++++ \\
MHC class II & ++ & ++++
\end{tabular}

* It was necessary to use a semiquantitative rating of severity (from + indicating rare positive cells to ++++ indicating very numerous positive cells) because of the focal distribution of the inflammatory lesions. †both leukocytes and endothelial cells.

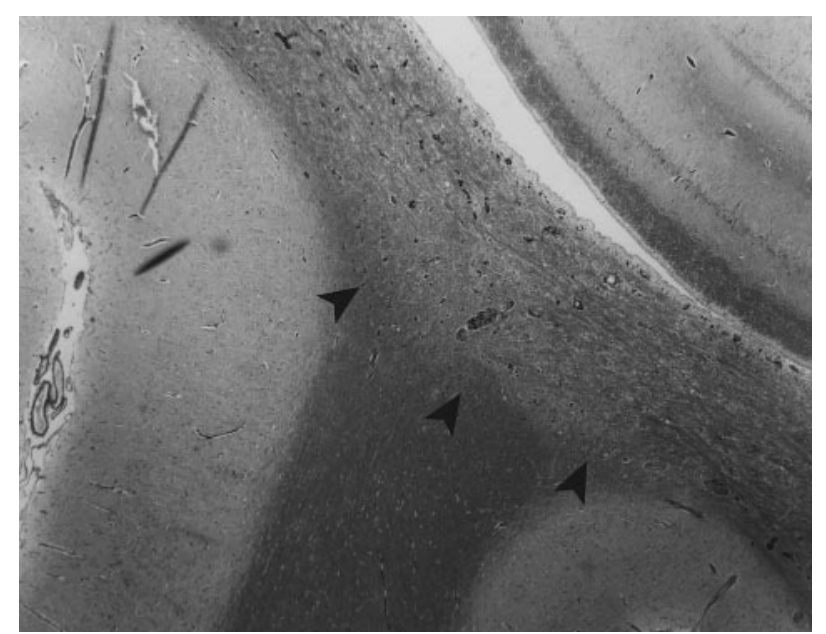

Figure 4 Section of brain from sheep 159 inoculated intracerebrally with the neurovirulent strain of OvLV demonstrating periventricular encephalitis and demyelination of the periventricular white matter (outlined by arrowheads). LFB/PAS stain, magnification $\times 25$.

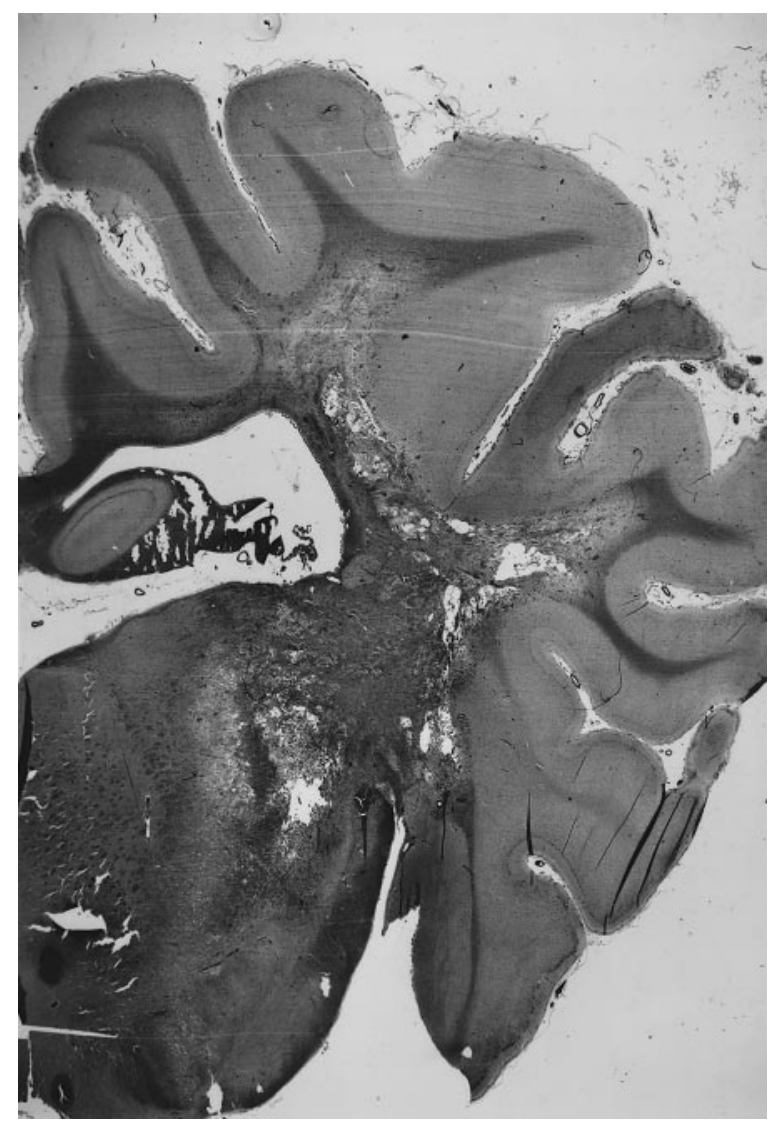

Figure 5 Brain from sheep 167 inoculated intracerebrally with the neurovirulent strain of OvLV and euthanized one year after inoculation. There is severe encephalitis with cavitation of the periventricular white matter. Demyelination of the cortical white matter is present. $\mathrm{H} \& \mathrm{E}$ stain, magnification $\times 2.5$. 
in the consolidated lung. Although there were numerous RCA-1 positive macrophages in the brain, few cells had detectable levels of viral RNA (Figure 6). Many of the perivascular macrophages in the brain also demonstrated TNF- $\alpha$ expression by in situ hybridization (Figure 7).

Results of immunohistochemical staining of brain tissue of sheep 159 are summarized in Table 1. The brain of sheep 159 stained intensely for MHC Class II antigen on inflammatory cells and endothelium. Many $\mathrm{T}$ cells were present throughout the brain, most numerous in areas of inflammation, but also scattered throughout the parenchyma and adjacent to vessels. $\mathrm{CD}^{+} \mathrm{T}$ cells were the most

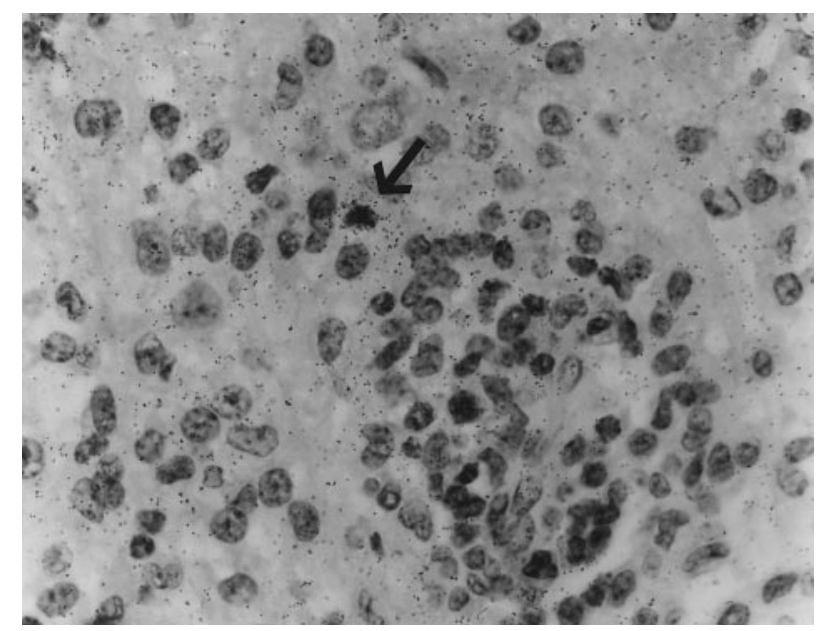

Figure 6 Radioactive in situ hybridization for viral RNA of brain from sheep 159 inoculated intracerebrally with the neurovirulent strain of OvLV showing a positive cell in the perivascular parenchyma (arrow). Hematoxylin counterstain, magnification $\times 630$.

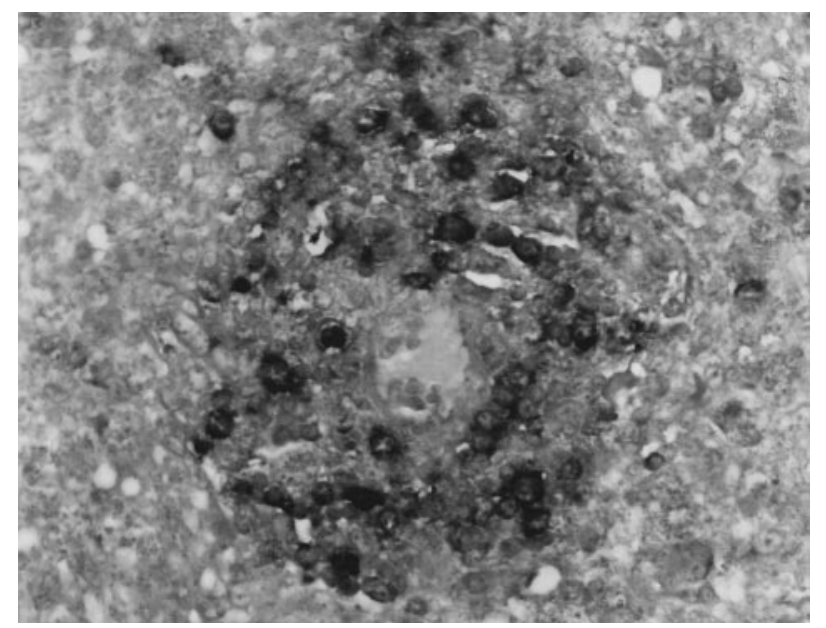

Figure 7 Digoxigenin in situ hybridization for TNF- $\alpha$ on frozen sections of brain from sheep 155 inoculated intracerebrally with the neurovirulent strain of OvLV showing numerous positive cells in a perivascular cuff. Hematoxylin counterstain, magnification $\times 400$ numerous, but there were also large numbers of $\mathrm{CD}^{+} \mathrm{T}$ cells. Scattered naive and $\gamma \delta \mathrm{T}$ cells were also seen within areas of intense inflammation and in perivascular cuffs.

Intra bone marrow (I/BM) inoculation Three 6month-old Border Leicester sheep $(165,173,174)$ were inoculated I/BM with the neuroadapted virus. Culture of PBMC within the first 2 weeks after inoculation indicated that all animals were infected. Virus was cultured from cerebrospinal fluid (CSF) cells of all three animals within the first month after inoculation. None of the three animals developed neutralizing antibodies to the virus. Sheep killed 8 months (173) and 1 year (174) after inoculation had no significant lesions at necropsy. A third sheep (165), killed at 10 months postinoculation, was cachexic and had severe lymphocytic interstitial pneumonia typical of OvLV infection. None of these sheep had pathological changes in the brain. Numerous cells containing viral RNA were seen in the lungs of the sheep with pneumonia, but viral RNA was not detected in the brain of any of these sheep. Together these data indicated that the neuroadapted strain of virus, although capable of inducing severe encephalitis when inoculated directly into the brain (i.e. was neurovirulent), was unable to invade the brain when inoculated I/BM (i.e. was not neuroinvasive).

\section{Viral load}

Viral load varied greatly among different animals and among tissues of individual animals. In general, animals with clinical disease had high virus burdens (approximately one infected cell per $10^{3}$ ) especially in tissues with inflammation, whereas healthy infected animals had extremely low virus burdens (approximately one infected cell per $10^{6}$ ). Table 2 illustrates these variations. The virus in tissues with lesions was present both as cell-free virus (detected by inoculating cell-free homogenates onto indicator macrophage cultures) and cellassociated virus (detected by co-culturing tissue cells with uninfected macrophages or goat synovial membrane cells). Cell-free homogenates of these tissues had virus titers varying from $10^{2}$ to $10^{5}$ $\mathrm{TCID}_{50} / \mathrm{mL}$. High concentrations of cell-free virus were found mainly in homogenates of pneumonic lungs and low titers in homogenates of draining lymph nodes (mediastinal). Only the sheep inoculated I/C with the neuroadapted virus had detectable virus in the brain. Synovial fluid of arthritic joints usually had a low level of cell-free virus also. Cell-free virus was never detected in plasma or in homogenates of other tissues including lymph nodes draining non-target organs. However, macrophages from dispersed cells or explants of the bone marrow and lymphoid tissues and peripheral blood derived macrophages (PBDM) usually produced cell-free virus in culture. Thus, while infected 
macrophages were present in tissue, virus replication in tissue was restricted.

Replication in vitro of parental and neuroadapted viruses

Viral growth curves as measured by reverse transcriptase (RT) activity in the supernatant of goat synovial membrane (GSM) cells and microglia inoculated with parent (93) and neuroadapted (155) viruses revealed differences in the in vitro cell tropism of the two viruses. Virus 93 achieved a much higher (20-fold) level of infection in GSM than the neuroadapted virus 155 (Figure 8). Conversely, the microglial cultures supported a higher (threefold) level of infection by the neuroadapted virus (155) than the parent virus (93) (Figure 9). These findings are consistent with the adaptation of the virus to replicate more efficiently in a specific tissue. The virus isolated from the joint replicated more efficiently in synovial-derived cells and the brain-passaged virus replicated more efficiently in microglia.

\section{Discussion}

This study was undertaken to determine whether the differences in tissue localization of lesions seen with ovine lentiviral disease are related to replication of tissue-specific virus strains. We chose the CNS as a target tissue because it is historically

Table 2 Comparison of OvLV lesions and viral load in sheep naturally infected, inoculated with neurovirulent virus intracerebrally (I/C), and inoculated with neurovirulent virus intra bone marrow (I/BM)

\begin{tabular}{|c|c|c|c|c|}
\hline Parameter & Sheep 93 & Sheep 159 & Sheep 165 & Sheep 173 \\
\hline Virus origin & natural infection & neurovirulent virus I/C & neurovirulent virus I/BM & neurovirulent virus I/BM \\
\hline Clinical signs & $\begin{array}{l}\text { dyspnea, cachexia, } \\
\text { swollen joints }\end{array}$ & $\begin{array}{c}\text { ataxia, dyspnea, } \\
\text { cachexia }\end{array}$ & dyspnea, cachexia & healthy \\
\hline Histology & pneumonia, synovitis & encephalitis, pneumonia & pneumonia & mild pneumonia \\
\hline \multicolumn{5}{|c|}{ Cell-free virus in tissue homogenates (TCID ${ }_{50}$ in GSM cells) } \\
\hline Synovial fluid & $10^{2}$ & NA\# & NA & NA \\
\hline Brain & 0 & $10^{2}$ & 0 & 0 \\
\hline Lung & $10^{4}$ & $10^{5}$ & $10^{5}$ & 0 \\
\hline Mediastinal LN & $\mathrm{ND}^{*}$ & $10^{2}$ & $10^{3}$ & 0 \\
\hline Mesenteric LN & 0 & 0 & 0 & 0 \\
\hline Spleen & 0 & 0 & 0 & 0 \\
\hline $\begin{array}{l}\text { Frequency of PBMC } \\
\text { with virus }\end{array}$ & $1 / 10^{3}$ & $1 / 10^{3}$ & $1 / 10^{3}$ & $1 / 10^{6}$ \\
\hline Neutralizing antibodies & 0 & 0 & 0 & 0 \\
\hline
\end{tabular}

*ND-not done, \#NA-not applicable, no excess synovial fluid, LN-lymph node.

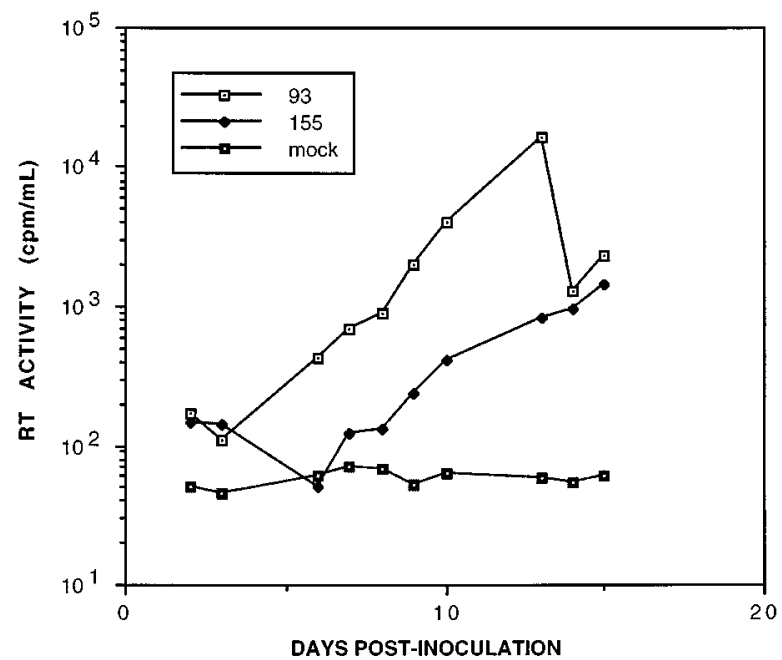

Figure 8 Growth curve demonstrating a 20-fold higher level of infection in cultured GSM cells by the parent virus isolated from the joint (93 virus) than by the neuroadapted virus (155 virus).

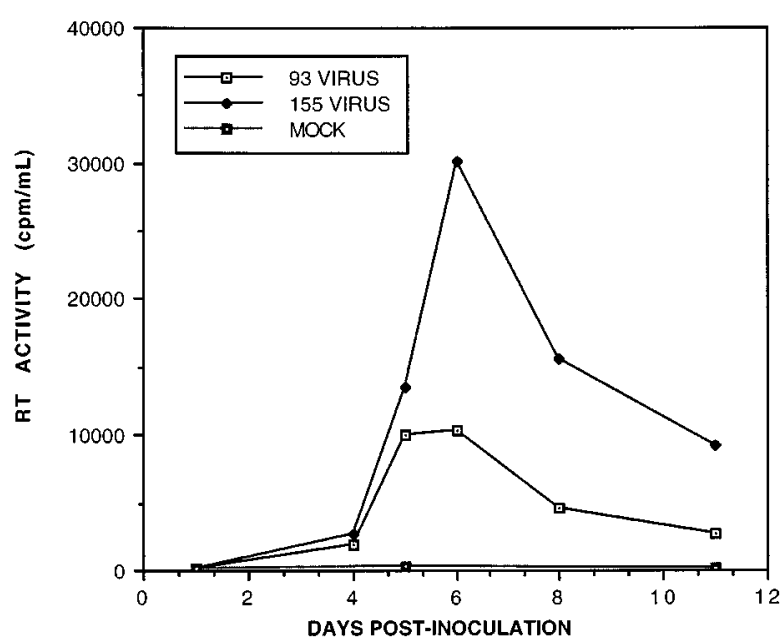

Figure 9 Growth curve demonstrating a 3-fold higher level of infection in cultured microglia by the neuroadapted virus (155 virus) than by the parent virus (93 virus). 
known as a site of replication by both ovine and primate lentiviruses including HIV and SIV and because of epidemiological observations suggesting that neurotropic viruses may be distinct from other viruses in the host (Levy, 1996; Palsson, 1976). In this study, virus isolated from joint fluid caused persistent infection and pneumonia and/or arthritis in four of six sheep, but did not cause encephalitis in any of the animals, even after up to 5 years of persistent infection. The possibility that the virus was potentially neurotropic but could not breach the blood-brain-barrier was addressed by inoculating the field virus directly into the brain. Failure to cause encephalitis under these conditions indicated that this agent was not neurovirulent.

Sequential intracerebral passage of this parent virus resulted in isolation of a variant that caused severe encephalitis in four of four sheep inoculated intracerebrally. Virus gene expression in the brain of these sheep was detected by in situ hybridization and infectious virus was detected by coculture of brain homogenates with susceptible cells. The low level of detectable viral gene expression is consistent with the restricted viral replication that is the hallmark of lentivirus infection (Haase et al, 1976; Johnson et al, 1996). In vitro studies demonstrated that this brain-adapted virus replicated more efficiently in microglia and less efficiently in GSM than the parental virus. HIV tropism for microglia has also been demonstrated in vitro and has been shown to be determined by the same regions of the env that determine macrophage tropism (Sharpless et al, 1992; Watkins et al, 1990).

The neuroadapted strain of OvLV replicated and caused lesions in the brain only when inoculated directly into the brain. The virus was unable to invade the CNS when inoculated I/V, S/Q, or I/BM and thus lacked neuroinvasive properties. Thus, additional viral changes are required to allow breach of the blood-brain barrier and invasion of the CNS. These data suggest that the molecular determinants of neurovirulence and neuroinvasiveness are separate. Similar disassociation of neurovirulence and neuroinvasiveness has been shown in SIVmac (Sharma et al, 1992).

Virus was detected in cells in the cerebrospinal fluid as early as 2 weeks after virus inoculation into the bone marrow, yet no infection of the brain was detected terminally. Similar early detection of virus in the CNS is seen HIV infection in people and in experimental infection in macaques with SIVmac (Davis et al, 1992; Koyanagi et al, 1987; Lackner et al, 1994; Narayan et al, 1985).

Immunohistochemical staining demonstrated intense expression of MHC Class II antigen and infiltration of $\mathrm{CD}^{+}$and $\mathrm{CD}^{+}{ }^{+} \mathrm{T}$ cells and macrophages in encephalitic brain. Similar findings have been reported in Icelandic sheep infected with visna virus (Georgsson, 1994; Torsteinsdóttir et al, 1992). These findings are in contrast to HIV and SIV encephalitis in which there is limited infiltration of lymphocytes (Budka, 1991). Since lymphocytes are not a significant target cell of OvLV, their numbers are not reduced and they migrate into the CNS in response to cytokines produced by activated macrophages in the CNS (Gorrell et al, 1992; Nathanson et $a l, 1976)$. TNF- $\alpha$ expression was detected in many of the perivascular macrophages in the brain. TNF- $\alpha$ is a proinflammatory cytokine with a wide variety of actions that could contribute to CNS inflammation including upregulation of IL-1 and IL-6 expression, activation of lymphocytes and macrophages, and increased cell adhesion molecule expression by endothelial cells (Abbas et al, 1991). TNF- $\alpha$ is elevated in the brains of patients with HIV dementia (Wesselingh et al, 1993) and as in OvLV is produced primarily by perivascular macrophages (Wesselingh et al, 1997).

The lack of neutralizing antibodies in the sheep in this study is consistent with other studies of American OvLV which appears to be similar to caprine arthritis-encephalitis virus (CAEV) in its ability to mask epitopes (Huso et al, 1988; Johnson et al, 1992). This is in contrast to Icelandic OvLV which induces a strong neutralizing antibody response (Kennedy-Stoskopf and Narayan, 1986).

Data from this study suggest that virus strains that cause CNS lesions have a tropism for brain macrophages over non-macrophage cells. Similar conclusions were drawn from studies on the neuropathogenesis of SIV infection in macaques in which the neurovirulent viruses replicated preferentially in brain macrophages (Koyanagi et al, 1987; Watry et al, 1995). It is possible that the molecular basis for neurological disease may lie not only in those viral sequences that confer upon the virus the ability to replicate in macrophages in general, but to replicate in brain macrophages in particular. A virus strain with a specific tissue tropism is most probably selected by that tissue from among the numerous mutant viruses present in the highly mutational lentivirus swarm. The fact that neurological disease in sheep is relatively rare in nature may indicate that neuroinvasive, neurovirulent variants are poorly represented in the virus swarm.

\section{Materials and methods}

\section{Cell cultures}

Goat synovial membrane (GSM) cells GSM cells were derived by explanting carpal synovial membranes from newborn colostrum-deprived goats and were propagated in minimum essential medium (MEM) containing glutamine, HEPES buffer, and gentamicin with fetal bovine serum (FBS) (heat inactivated $56^{\circ} \mathrm{C} / 30 \mathrm{~min}$ ) at concentrations of $10 \%$ and $1 \%$ used for growth and maintenance, respectively. These cells were used to cultivate stocks of OvLV (Zink and Narayan, 1989). 
Peripheral blood-derived macrophages (PBDM)

Peripheral blood mononuclear cells (PBMC) were separated from heparinized blood of virus-negative donor sheep by centrifugation on FicollHypaque gradients (Zink and Narayan, 1989). The cells were suspended in polypropylene tubes at a concentration of $2 \times 10^{6}$ cells $/ \mathrm{mL}$ in RPMI supplemented with glutamine, HEPES buffer, 2mercaptoethanol, gentamicin, and $20 \%$ lamb serum (heat inactivated $56^{\circ} \mathrm{C} / 30 \mathrm{~min}$ ) and cultured at $37^{\circ} \mathrm{C}$ in a humidified incubator to enhance the growth and differentiation of macrophages. After 5 days in culture nonadherent lymphocytes were removed by washing leaving only the PBDM (Gorrell et al, 1992).

Microglia Sheep brains obtained from a local slaughterhouse within $30 \mathrm{~min}$ of death were minced, homogenized, digested with collagenase/dispase, and passed through $183 \mathrm{~mm}$ and $53 \mathrm{~mm}$ sieves to isolate a mixed population of loose cells. These were plated in tissue culture flasks in Dulbecco's minimum essential medium (DMEM) with $10 \%$ FBS. After 3 weeks in culture, the cultures were trypsinized and washed three times to remove all cells except the tightly adherent microglia, which were then identified by uptake of rhodamine-conjugated Diacyl LDL.

\section{Assay of virus infectivity}

Infectivities of cell-free homogenates of tissues and tissue culture supernatants were titered in GSM cells by inoculating tenfold dilutions of test material onto semiconfluent cultures of GSM cells in microtiter plates (four wells per dilution) and the cells examined for cytopathic effect (fusion) 10-14 days later.

\section{Reverse transcriptase assay}

Supernatants of GSM and microglia cultures were assayed for reverse transcriptase (RT) activity as a cytopathic effect-independent measure of virion numbers. Following centrifugation at $25000 \mathrm{~g}$ for $1 \mathrm{~h}$, the virus pellet was resuspended and lysed in a solution of $50 \mathrm{mM}$ Tris-HCl (pH 8.3), $20 \mathrm{mM}$ dithiothreitol (DTT) and $0.25 \%$ Triton X-100. The samples were then incubated at $37^{\circ} \mathrm{C}$ for $2 \mathrm{~h}$ in $50 \mathrm{mM}$ Tris-HCl (pH 7.9), $50 \mathrm{mM} \mathrm{KCl,} 5 \mathrm{mM}$ $\mathrm{MgCl}_{2}, 0.05 \%$ Nonidet P-40, $0.33 \mathrm{~A}_{260}$ units $/ \mathrm{ml}$ of poly(rA)-poly $(\mathrm{dT})_{12-18}, 10 \mathrm{mM}$ ethylene glycol-bis [- aminoethyl ether]-N, N, N, N'-tetraacetic acid (EGTA), and $0.5 \mathrm{M}\left[{ }^{3} \mathrm{H}\right]$ thymidine $5^{\prime}$-triphosphate (TPP) $(62 \mathrm{Ci} / \mathrm{mmol})$. Each sample was spotted onto ion exchange paper. The filters were washed three times in $0.35 \mathrm{M} \mathrm{Na}_{2} \mathrm{HPO}_{4}$, rinsed briefly in distilled $\mathrm{H}_{2} \mathrm{O}$, and once in $95 \%$ ethanol. After air drying, the radioactivity in the filters was measured in solution with a Tri-Carb liquid scintillation analyzer.

\section{Infectious center assay}

The number of infected cells in cell suspensions derived from tissues was determined by inoculating doubling dilutions of test cells into tubes containing indicator macrophages which were then assayed for infectivity as described above. The tube containing the highest dilution of test cells with fusion was assumed to have originated from a single cell. The ratio of infected cells to the total number of cells inoculated provided the index of infectivity.

\section{Virus neutralization}

Approximately $50 \mathrm{TCID}_{50}$ of virus were incubated with doubling dilutions of serum at $37^{\circ} \mathrm{C}$ for $60 \mathrm{~min}$, then the virus antibody mixtures were added to cultures of indicator macrophages. These were then evaluated for infectivity 10 days later by adding GSM cells and observing the cocultures for fusion as described above.

\section{Parent virus}

The donor animal for the parent virus was a yearling Border Leicester ram (93) with severe synovitis, pneumonia, and cachexia but no neurological lesions. Macrophages from the synovial fluid of this ram were cultivated in medium used for propagation of PBDM. Supernatant fluid collected 14 days later was frozen at $-80^{\circ} \mathrm{C}$ in aliquots and used as virus stock. This virus had a titer of $10^{4} \mathrm{TCID}_{50} / \mathrm{mL}$ in PBDM and $10^{3} \mathrm{TCID}_{50} / \mathrm{mL}$ in GSM cells. PBMC (one infected cell per $10^{3}$ ) from this donor sheep were also used to inoculate some animals.

\section{Inoculation of sheep}

Border Leicester and mixed-breed sheep were used for inoculation by the I/V, SQ, I/C, and I/BM routes. Animals inoculated intracerebrally or in the bone marrow were anesthetized with halothane. Intracerebral inoculations consisted of $100 \mu \mathrm{L}$ of sheep brain homogenates containing $10^{2} \mathrm{TCID}_{50} / \mathrm{mL}$ (animal passage) or $100 \mu \mathrm{L}$ tissue culture supernatants containing $10^{5} \mathrm{TCID}_{50} / \mathrm{mL}$ virus. Sheep inoculated $\mathrm{I} / \mathrm{V}, \mathrm{SQ}$ or I/BM were given $1 \mathrm{~mL}$ of tissue culture supernatants containing $10^{5} \mathrm{TCID}_{50}$ of virus $/ \mathrm{mL}$. Inoculations had no immediate adverse effects.

In vivo viral passage

The parent virus was passed seven times sequentially in the brains of 6-12 month-old Border Leicester sheep as outlined in Figure 1. Each sheep was inoculated I/C and I/BM with virus or virusinfected cells/tissue homogenate from previously inoculated sheep.

Blood, cerebrospinal fluid (CSF) and bone marrow from inoculated animals were examined at weekly intervals during the first month and monthly thereafter to monitor infection. CSF was obtained by lumbar puncture under halothane anesthesia. Bone marrow was aspirated via heparinized human bone marrow biopsy needles from 
limbs other than the inoculated one under halothane anesthesia. Heparinized peripheral blood was collected by jugular venipuncture.

The sheep were killed from 6-8 weeks after inoculation and samples of peripheral blood, CSF, bone marrow, and brain, and in some cases, lung, spleen and lymph nodes, were taken to prepare further inocula and to assay infectivity. Cell-free homogenates of brain were prepared by grinding a portion of the tissue in frozen mortars in MEM $+5 \%$ FBS (10\% wt/vol), passing the material through a Dounce homogenizer and clarifying by centrifugation at $1000 \mathrm{~g}$ for $10 \mathrm{~min}$. Minced fragments of brain were also explanted in tissue culture flasks using $4 \mathrm{~mL}$ of MEM+20\% lamb serum per $75 \mathrm{~cm}^{2}$ flask for 1 week and $10 \mathrm{ml}$ of medium thereafter. This procedure yielded florid cultures of tissue macrophages. Cell suspensions were obtained from spleen and/or peripheral lymph node by teasing cells from the parenchyma, washing twice by centrifugation at $200 \mathrm{~g}$ for $5 \mathrm{~min}$ and resuspending in MEM with $10 \%$ FBS. Bone marrow cells were washed twice by centrifugation at $200 \mathrm{~g}$ for $5 \mathrm{~min}$ and resuspended in MEM with $10 \%$ FBS. Red blood cells were lysed in a hypotonic salt solution. CSF cells were separated and washed as for bone marrow. Virus infectivities of the homogenates, cell suspensions and culture supernatants were determined in GSM cells and PBDM as described and samples to be used for further viral passages were stored at $-80^{\circ} \mathrm{C}$.

Complete postmortem examinations were performed on all sheep and tissues were fixed in $10 \%$ buffered formalin and snap-frozen in liquid nitrogen for histology, immunohistochemistry, and in situ hybridization.

\section{In situ hybridization}

To detect OvLV RNA Formalin-fixed, paraffinembedded tissue sections were deparaffinized in a graded alcohol series and pretreated with $0.2 \mathrm{~N} \mathrm{HCl}$ and $25 \mathrm{mg} / \mathrm{mL}$ proteinase $\mathrm{K}$. The tissues were then acetylated, dehydrated through a graded alcohol series and air-dried as previously described (Zink et al, 1990). In situ hybridization was performed using a $2.3 \mathrm{~kb}$ molecular clone of ovine lentivirus, provided by Dr M Gonda, consisting of the majority of the pol gene. The DNA was radiolabeled by nick translation using $\left[{ }^{35} \mathrm{~S}\right] \mathrm{dATP}$ and $\left[{ }^{35} \mathrm{~S}\right] \mathrm{dCTP}$ and a DNAse concentration of $25 \mu \mathrm{g} / \mathrm{mL}$ to produce DNA fragments of approximatley $40-70$ base pairs as previously described (Moench et al, 1985). Specific activities of the radiolabeled DNA probes were greater than $7 \times 10^{8}$ c.p.m./mg. Radiolabeled DNA $(0.2 \mu \mathrm{g} / \mathrm{mL})$ was denatured by heating and placed over the pretreated tissues. After hybridization (16 h at room temperature), the slides were washed, dehydrated, dipped in NTB3 autoradiographic emulsion, air-dried and developed after three to ten days exposure in the dark. Slides were examined by light microscopy; the presence of viral RNA was indicated by silver grains over cells. Uninfected and visna virus-infected GSM cells and tissues and a non-specific radiolabeled probe (usually simian immunodeficiency virus) were used as controls.

To detect TNF- $\alpha$ Tissue sections were treated with $1.5 \mu \mathrm{g} / \mathrm{ml}$ proteinase $\mathrm{K}$ for $15 \mathrm{~min}$ at $37^{\circ} \mathrm{C}$, acetylated and then prehybridized for $2 \mathrm{~h}$ at $52^{\circ} \mathrm{C}$. Hybridization was performed overnight at $52^{\circ} \mathrm{C}$ in a solution containing $50 \%$ formamide (v/v), $4 \times$ SSC (sodium chloride/sodium citrate buffer), $2 \times$ Denhard's reagent, 10\% Dextran sulfate (w/v), $500 \mu \mathrm{g} /$ ml blocking RNA (calf liver RNA) and $1 \mu \mathrm{g} / \mathrm{ml}$ digoxigenin-labeled RNA probe. Unbound labeled RNA probe was removed by a RNAse treatment for $30 \mathrm{~min}$ at $37^{\circ} \mathrm{C}$ and by two $15 \mathrm{~min}$ washes in $0.2 \times \mathrm{SSC}$ at $50^{\circ} \mathrm{C}$. Bound probe was detected with anti-digoxigenin antibody Fab fragments conjugated with alkaline phosphatase and color reaction was performed with NBT (nitro blue tetrazolium) and 5-bromo-4-chloro-3-indolyl phosphate. The cDNA of ovine TNF- $\alpha$ (kindly donated by Dr HF Seow, CSIRO, Parkville, Australia) was cloned in pSPT19. The antisense probe and control sense probe were transcribed in vitro from the T3 or SP6 promoter in the presence of digoxigenin-UTP. Labeled probes were sheared by alkaline hydrolysis to yield RNA of approximatley 150 nucleotides in length.

\section{Immunohistochemistry}

Cryostat sections were prepared and fixed for $10 \mathrm{~min}$ in $100 \%$ ethanol containing $0.8 \% \mathrm{H}_{2} \mathrm{O}_{2}$ to remove endogenous peroxidase. The monoclonal antibodies (MAb) used to detect leukocyte differentiation antigens in the CNS of inoculated animals are listed in Table 3. MAb 86D that recognizes sheep $\gamma \delta$ T cell recepter was a gift of Dr CR MacKay, Basel, Switzerland. The other MAbs were provided by Dr M Brandon, Melbourne, Australia. Tissue sections were stained by the immunoperoxidase technique as previously described (Gorrell et al, 1992). Briefly,

Table 3 Monoclonal antibodies and lectins used to detect sheep differentiation and activation antigens

\begin{tabular}{lcc}
\hline Antigen & Specificity & Designation \\
\hline CD2 & T cells and NK cells & $36 \mathrm{~F} \dagger$ \\
CD4 & helper T cells & $44.38,44.97 \dagger$ \\
CD8 & cytotoxic/suppressor T cells & $38.65 \dagger$ \\
CD5 & T cells and B cell subset & $25.91 \dagger$ \\
CD45RA & naive T cells & $20.96 \dagger$ \\
$\gamma \delta$ & gamma-delta T cells & $86 \mathrm{D} \dagger$ \\
MHC II & activated cells & $49.1 \dagger$ \\
RCA I & macrophages and microglia & $\S$ \\
\hline
\end{tabular}

$\uparrow$ Provided by Dr M Brandon, Melbourne, Australia. \$Provided by Dr CR Mackay, Basel, Switzerland. §Ricinus communis agglutinin I (Vector Laboratories, Burlingame, California). 
primary antibody was applied to the tissues for $2 \mathrm{~h}$ at room temperature. The tissues were washed in PBS followed by distilled water, peroxidase-conjugated secondary antibody was applied and the sections were incubated for $1 \mathrm{~h}$. The sections were then washed and diaminobenzidine tetrahydrochloride (DAB) in citrate buffer containing $0.01 \% \quad \mathrm{H}_{2} \mathrm{O}_{2}$ was applied to the sections for $10 \mathrm{~min}$. The sections were washed, counterstained with hematoxylin, dehydrated, mounted and examined.

\section{Lectin histochemistry}

Biotinylated Ricinus communis agglutinin I lectin (RCA-I) was used to detect cells of monocytemacrophage lineage in formalin-fixed, paraffinembedded sections. The tissue sections were overlaid with RCA-I diluted $1: 500$ in Tris $(0.50 \mathrm{mM}$, pH 7.6) and incubated at room temperature for $1 \mathrm{~h}$. The tissues were washed in PBS and avidin-biotin complex was applied for $30 \mathrm{~min}$. The sections were

\section{References}

Abbas AK, Lichtman AH, Pober JS (1991). Cellular and Molecular Immunology. WB Saunders \& Co: Philadelphia, pp 230-231.

Andrésson OS, Elser JE, Georgsson G, Tobin GJ, Greenwood JD, Gonda MA, Andrésdóttir V, Pálsson PA, Pétursson G (1994). Pathogenic proviral molecular clone of neurovirulent visna virus. Ann NY Acad Sci 724: $133-139$.

Brinkmann R, Schwinn A, Narayan O, Zink MC, Kreth HW, Roggendorf W, Dorries R, Schwender S, Imrich H, Ter Meulen V (1992). Human immunodeficiency virus infection in microglia: Correlation between cells infected in the brain and cells cultured from infectious brain tissue. Ann Neurol 31: 361-365.

Budka H (1991). Neuropathology of human immunodeficiency virus infection. Brain Pathol 1: 163-175.

Cheng-Mayer C, Weiss C, Seto D, Levy JA (1989). Isolates of HIV-1 from brain may constitute a special group of AIDS viruses. Proc Natl Acad Sci 86: 8575-8579.

Constable PD, Meier WA, Foley GL, Morin D, Cutlip RC, Zachary JF (1996). Visna-like disease in a ram with chronic demyelinating encephalomyelitis. J Am Vet Med Assoc 208: 117-120.

Cutlip RC, Lehmkuhl HD, Brogden KA, Bolin SR (1985a). Mastitis associated with ovine progressive pneumonia virus infection in sheep. Am J Vet Res 46: 326-328.

Cutlip RC, Lehmkuhl HD, Wood RL, Brogden KA (1985b). Arthritis associated with ovine progressive pneumonia. Am J Vet Res 46: 65-68.

Cutlip RC, Lehmkuhl HD, Schmerr MJ, Brogden KA (1988). Ovine progressive pneumonia (maedi-visna) in sheep. Vet Microbiol 17: 237-250.

Davis LE, Hjelle BL, Miller VE, Palmer DL, Llewellyn AL, Merlin TL, Young SA, Mills RG, Wachsman W, Wiley CA (1992). Early viral brain invasion in iatrogenic human immunodeficiency virus infection. Neurology 42: 1736-1739. washed again, DAB was applied for $10 \mathrm{~min}$, and the sections were washed, dehydrated, mounted and examined.

Viral growth curves on GSM and microglia

Semiconfluent primary cultures of GSM and microglia were inoculated with GSM-PBDM coculture supernatants of equal RT activities $\left(10^{5}\right.$ c.p.m. $/ 10^{5}$ cells) of the parent (93) or the brain-passaged (155) virus that had been passaged on both PBDM and GSM cells. Total supernatants were clarified by centrifugation and assayed for RT activity.

\section{Acknowledgements}

We thank Dr M Gonda for providing us with cloned OPPV DNA. This work was supported by NIH grants NS28357, NS12127, NS23039, RR6753, and AI-32369.

DeMartini JC, Brodie SJ, de la Concha-Bernejillo A, Ellis JA, Lairmore MD (1993). Pathogenesis of lymphoid interstitial pneumonia in natural and experimental ovine lentivirus infection. Clin Inf Dis 17: S236S242.

Desrosiers RC, Hansen-Moosa A, Mori K, Bouvier DP, King NW, Ringler DJ (1991). Macrophage-tropic variants of SIV are associated with specific AIDSrelated lesions but are not essential for the development of AIDS. Am J Pathol 139: 29-35.

Eilbott DJ, Peress N, Burger H, LaNeve D, Orenstein J, Gendelman HE, Seidman R, Weiser B (1989). Human immunodeficiency virus type 1 in spinal cords of acquired immunodeficiency syndrome patients with myelopathy: expression and replication in macrophages. Proc Natl Acad Sci 86: 3337-3341.

Epstein LG, Kuiken C, Blumberg BM, Hartman S, Sharer LR, Clements M, Goudsmit J (1991). HIV-1 V3 domain variation in brain and spleen of children with AIDS: tissue-specific evolution within host-determined quasispecies. Virology 180: $583-590$.

Georgsson G (1994). Neuropathological aspects of lentiviral infections. Ann NY Acad Sci 724: 50-67.

Gorrell MD, Brandon MR, Sheffer D, Adams RJ, Narayan O (1992). Ovine lentivirus is macrophage tropic and does not productively infect $\mathrm{T}$ lymphocytes. $J$ Virol 66: $2679-2688$.

Haase AT, Stowring L, Narayan O, Griffin D, Price D (1976). Slow persistent infection caused by visna virus: Role of host restriction. Nature 195: 175-177.

Huso DL, Narayan O, Hart GW (1988). Sialic acids on the surface of caprine arthritis-encephalitis virus define the biological properties of the virus. J Virol 62: $1974-1980$. 
Johnson LK, Meyer AL, Zink MC (1992). Detection of ovine lentivirus in seronegative sheep by in situ hybridization, PCR, and cocultivation with susceptible cells. Clin Immunol Immunopathol 65: $254-260$

Johnson RT, Glass JD, McArthur JC, Chesebro BW (1996). Quantitation of human immunodeficiency virus in brains of demented and nondemented patients with acquired immunodeficiency syndrome. Ann Neurol 39: $392-395$

Kennedy-Stoskopf S, Narayan O (1986). Neutralizing antibodies to visna lentivirus: mechanism of action and possible role in virus persistence. J Virol 59: $37-$ 44.

Kennedy-Stoskopf S, Narayan O, Strandberg JD (1985). The mammary gland as a target organ for infection with caprine arthritis-encephalitis virus. I Comp Pathol 95: 609-617.

Koyanagi Y, Miles S, Mitsuyasu RT, Merrill JE, Vintners HV, Chen IS (1987). Dual infection of the central nervous system by AIDS viruses with distinct cellular tropisms. Science 236: 819-822.

Lackner AA, Vogel P, Ramos RA, Kluge JD, Marthas M (1994). Early events in tissues during infection with pathogenic (SIVmac239) and nonpathogenic (SIVmac1A11) molecular clones of simian immunodeficiency virus. Am J Pathol 145: 428-439.

Levy J (1996). Viral and immunological factors involved in HIV neuropathogenesis. J Neurovirol 2: 7.

Lutley R, Petursson G, Georgsson G, Palsson PA, Nathanson N (1985). Strains of visna virus with increased neurovirulence. ed. In: JM Sharp and R Hoff-Jorgensen (eds). Slow Viruses in Sheep, Goats and Cattle. Commission of the European Communities: Luxembourg, pp 45-49.

Moench TR, Gendelman HE, Clements JE, Narayan O, Griffin DE (1985). Efficience of in situ hybridization as a function of probe size and fixation technique. J Virol Methods 11: 119-130.

Narayan O, Clements JE (1989). Biology and pathogenesis of lentiviruses. J Gen Virol 70: 1617-1639.

Narayan O, Sheffer D, Clements JE, Tennekoon G (1985). Restricted replication of lentiviruses. Visna viruses induce a unique interferon during interaction between lymphocytes and infected macrophages. J Exp Med 162: $1954-1969$.

Nathanson N, Panitch HJ, Palsson PA, Petursson G, Georgsson G (1976). Pathogenesis of visna. II. Effect of immunosuppression upon early central nervous system lesions. Lab Invest 35: 444-451.

Oliver RE, Gorham JR, Parish SF, Hadlow WJ, Narayan O (1981). Ovine progressive pneumonia: Pathologic and virologic studies on the naturally occurring disease. Am J Vet Res 42: 1554-1559.

Palsson PA (1976). Maedi and visna in sheep. Front Biol 44: $17-43$.
Schultheiss PC (1985). Visna-like disease in a Minnesota sheep. J Am Vet Med Assoc 186: 811.

Sharma DP, Zink MC, Anderson M, Adams R, Clements JE, Joag SV, Narayan O (1992). Derivation of neurotropic simian immunodeficiency virus from exclusively lymphocytetropic parental virus: pathogenesis of infection in macaques. J Virol 66: $3550-3556$

Sharpless NE, O’Brien WA, Verdin K, Kufta CV, Chen ISY, Dubois-Dalcq M (1992). Human immunodeficiency virus type 1 tropism for brain microglial cells is determined by a region of the env glycoprotein that also controls macrophage tropism. $J$ Virol 66: $2588-2593$.

Sheffield WD, Narayan O, Strandberg JD, Adams RJ (1980). Visna-maedi-like disease was associated with an ovine retrovirus infection in a Corriedale sheep. Vet Pathol 17: 544-552.

Sigurdsson B, Plasson PA, Grimsson H (1957). Visna, a demyelinating transmissible disease of sheep. $J$ Neuropathol Exp Neurol 16: 389-403.

Torsteinsdóttir S, Georgsson G, Gísladóttir E, Rafnar B, Pálsson PA, Pétursson G (1992). Pathogenesis of central nervous system lesions in visna: Cellmediated immunity and lymphocyte subsets in blood, brain and cerebrospinal fluid. $J$ Neuroimmunol 41: 149-158.

Watkins BA, Dorn HH, Kelly WB, Armstrong RC, Potts BJ, Michaels F, Kufta CV, Dubois Dalcq M (1990). Specific tropism of HIV-1 for microglial cells in primary human brain cultures. Science 249: 549-553.

Watry D, Lane TE, Streb M, Fox HS (1995). Transfer of neuropathogenic simian immunodeficiency virus with naturally infected microglia. Am J Pathol 146: 914923.

Wesselingh SL, Power C, Glass JD, Tyor WR, McArthur JC, Farber JM, Griffin JW, Griffin DE (1993). Intracerebral cytokine messenger RNA expression in acquired immunodeficiency syndrome dementia. Ann Neurol 33: $576-582$.

Wesselingh SL, Takahashi K, Glass JD, McArthur JC, Griffin JW, Griffin DE (1997). Cellular localization of tumor necrosis factor mRNA in neurological tissue from HIV-infected patients by combined reverse transcriptase/polymerase chain reaction in situ hybridization and immunohistochemistry. $J$ Neuroimmunol 74: 1-8.

Zink MC, Narayan O (1989). Lentivirus-induced interferon inhibits maturation and proliferation of monocytes and restricts the replication of caprine arthritis-encephalitis virus. J Virol 63: 2578-2584.

Zink MC, Yager JA, Myers JD (1990). Pathogenesis of caprine arthritis encephalitis virus. Cellular localization of viral transcripts in tissues of infected goats. Am J Pathol 136: 843-854. 